\title{
The Effect Of Shortening Lock-IN PeRIOdS IN TELECOMMUNICATION SERVICES
}

\author{
Baojiang Yang \\ Universidade Católica Portuguesa, Católica Lisbon School of Business and Economics, \\ Palma de Cima, 1649-023 Lisboa PORTUGAL \{youngchrisyang@gmail.com\} \\ Miguel Godinho de Matos \\ Universidade Católica Portuguesa, Católica Lisbon School of Business and Economics, \\ Palma de Cima, 1649-023 Lisboa PORTUGAL \{miguel.godinhomatos@ucp.pt\} \\ Pedro Ferreira \\ Heinz College, Carnegie Mellon University, 5000 Forbes Avenue, \\ Pittsburgh PA 15213 U.S.A. \{pedro@cmu.edu\}
}

\begin{abstract}
In this research note, we study the welfare implications of shortening the length of the lock-in period associated with triple play contracts using household level data, from a large telecommunications provider, for a period of 6 months. Using a multinomial logit model to explain consumer behavior we show that, in our setting, shortening the length of the lock-in period decreases the aggregated profit of the firms in the market more than it increases consumer surplus. This result arises because shortening the length of the lock-in period increases churn, and the costs to set up service for the consumers that churn and join a new carrier supersede the increase in the consumers' willingness to pay for service when the length of the lock-in period shortens.
\end{abstract}

Keywords: Lock-in periods, switching costs, telecommunications, multinomial logit

\section{Introduction}

In industries where customer acquisition is costly, firms typically opt for subscription-based business models locking consumers into long-term contracts. These contracts, often termed lock-in periods in the industry, aim to ensure that consumers stay with the firm long enough so that their monthly bills, accumulated over their tenure, cover not only the costs of maintenance and service provision but also the initial costs associated with consumer acquisition and service deployment/ activation (Farrell and Klemperer 2007). ${ }^{2}$

\footnotetext{
${ }^{1}$ Jonathan Wareham was the accepting senior editor for this paper. Sunil Wattal served as the associate editor.

${ }^{2}$ Examples of industries that share these characteristics include telecommunications, home security and surveillance, and several utilities where there is a need to deploy equipment at the consumer's premises to allow access and measurement of the services provided (e.g., electricity, water).
}

In this type of markets, consumers can still terminate contracts before lock-in periods are over. However, to do so, they need to pay a financial penalty, as established in the contract with the firm. These penalties are typically set in a way that allows firms to cover the costs incurred to set up service when customers join. Starting in the early 2000s, in the telecommunications sector, several firms offered contracts that locked-in consumers for long periods of time. For example, in the United Kingdom, Orange encouraged customers to sign up contracts with 24-month lock-in periods (Capgemini 2009). In Canada, Rogers Communications, BCE, and Telus offered contracts with 3-year lock-in periods for mobile phone service (CRTC 2012). Mobile firms in Asian countries such as South Korea, Japan, and China also offered contracts with 24-month lock-in periods around the same time.

From 2011 onward, there has been a regulatory push to shorten lock-in periods in telecommunications all around the 
world. In the European Union, the Telecommunications Law banned 3-year-long contracts by limiting the maximum lockin period to 24 months (European Union 2009). Other regions followed a similar approach. For example, in 2013, the Canadian Radio-television and Telecommunications Commission (CRTC) limited lock-in periods to 24 months and capped early cancellation fees to the subsidy provided by firms for device acquisition (CRTC 2013). More recently, in the United States, President Obama signed the "Unlocking Consumer Choice and Wireless Freedom Act" requiring U.S. carriers to unlock devices at the customer's request, thus allowing them to keep the same handset when switching providers (Congress 2013). The debate about lock-in periods has been reignited in recent times in countries such as the United Kingdom, Canada, and Denmark, and many regulators are now considering reducing these periods even further.

Lock-in periods are a particular case of switching costs and thus may hurt consumers by reducing their freedom to choose service providers (Klemperer 1987, 1995). However, a number of complex dynamic factors render the effect of switching costs on consumer surplus hard to predict (Dubé et al. 2009; Villas-Boas 2015). For example, when firms cannot exploit existing consumers, they are less likely to compete for them in the first place, which may increase prices and thus reduce consumer surplus (Cabral 2009). These complex dynamics suggest that measuring the impact of switching costs on welfare is essentially an empirical question, to which our study contributes by estimating how shortening lock-in periods to less than the current status quo of 24 months affects welfare. We focus on a market for triple-play services, which is now the dominant mode to consume telecommunications and media services both in the United States and in the European Union (OVUM 2015).

Our paper uses a dataset from a large triple-play telecommunications provider to study what happens to consumers and firms when the lock-in period is shortened. We use this dataset to estimate a multinomial logit model in which households can choose to keep the same service, change service inside the carrier, or churn. This model allows us to measure switching costs in dollar terms and simulate how changes in the length of the lock-in period affect both consumers and firms. In our empirical context, and in markets with two firms, we find that the average switching cost to change service inside the firm is $\$ 162$, whereas the average switching cost associated with churn is above $\$ 210$ and increases roughly $\$ 1$ per additional month of outstanding lock-in. More importantly, we also find that firms lose more profit than what consumers gain in surplus when lock-in periods shorten. For example, in our empirical context, and again, for when two firms compete, the average consumer surplus increases less than $\$ 16$ if the lock-in period is reduced from 24 to 16 months. However, the profits that the firms in the market collect from that representative consumer decrease more than $\$ 25$, showing that shortening the lock-in period reduces welfare. Similar results are obtained for different numbers of players in the market and for different reductions in the length of the lock-in period, lending robustness to our findings.

Our paper offers several unique contributions. First, we measure switching costs inside and outside the firm in dollar terms over the same time window, allowing us to compare them appropriately. Second, we show that regulators need to be very careful when considering shortening lock-in periods. Doing so increases consumer surplus but reduces firm profits and, as is usually the case, regulators need to ponder between these two opposing forces in a way that not only provides consumers flexibility but also ensures that carriers have sufficient incentive to be in business and maintain, or even upgrade, the quality of the services they provide. Third, our paper also shows that consumers become worse-off when firms react to shorter lock-in periods by increasing prices to keep their profits, that is, if firms do so then consumers would be better off if lock-in periods had not been shortened. This result arises because telecommunication markets have usually only a few firms that compete locally for many buyers, there are significant barriers to entry for firms, and one firm's actions have significant effects on the profitability of its rivals. This result shows that shortening lock-in periods to increase consumer surplus may also require regulators to regulate prices in markets where competition is imperfect, otherwise their interventions may backfire. These insights should prove valuable to regulators around the world now that several of them are looking into changing lock-in policies.

The remainder of our paper is organized as follows. The next section reviews the related work. The subsequent section describes our empirical context and provides descriptive statistics. We then introduce our model, present our estimates of switching costs, and describe several policy simulations studying the effect of shortening lock-in periods on consumer surplus and firm profits. Finally, we summarize our work and present conclusions.

\section{Literature Review}

Our paper is related to the empirical literature that measures switching costs, and thus it is closely linked to the active monitoring of switching costs performed by National Regulatory Authorities (NRAs). NRAs oversee switching costs and suggest legislation that governments may enforce to limit them. This is a complex task because regulators must consider the trade-off between consumer surplus and welfare, the 
latter defined as the sum of the former and firm profits. The regulator's task is not just one of fairly splitting welfare between consumers and firms, but also to look for ways to maximize overall well-being (Gans 2001). Conventional wisdom suggests that low switching costs are likely to increase consumer surplus (Klemperer 1995) because firms tend to enjoy significant advantages when switching costs are high. Firms are usually able to charge higher prices (Bijwaard et al. 2008; Lieberman and Montgomery 1998) to locked-in consumers, a strategy called bargain-then-rip-off (Klemperer 1987, 1995), which has been extensively documented using empirical data (Sharpe 1997; Shy 2002; Stango 2002; Viard 2007). With high switching costs, entrants also have a hard time to steal consumers that are locked-in to market leaders even if they offer better prices, which allows the latter to sustain their market shares over time.

However, and at the same time, low switching costs provide little incentive for firms to deploy infrastructure to provision service in the first place, which may reduce both consumer surplus and welfare (Farrell and Klemperer 2007). Low switching costs may result in additional adverse effects for consumers (Cabral 2009). For example, when firms cannot exploit existing consumers, they have little incentive to attract them in the first place (Doganoglu 2010; Dubé et al. 2009; Shin and Sudhir 2009), which may result in higher starting prices for consumers. Additionally, in markets where switching generates additional setup costs, low switching costs, leading to more frequent switching, generate more of such costs rendering the market less efficient (Gans 2001).

The theory of switching costs is rich in theoretical models. However, papers measuring these costs empirically are far scarcer. Exceptions include Borenstein (1991), who measured switching costs in the U.S. retail gasoline market; Knittel (1997), who showed how the presence of significant switching costs led to little change in the prices of long distance phone calls in the United States after the divestiture of AT\&T in 1984; Viard (2007), who studied the introduction of number portability for toll-free numbers in the United States and found that switching costs had an ambiguous effect on prices for firms that could not discriminate between existing and new consumers; Epling (2002), who studied competition in long distance telephony in the United States after the Telecom Act of 1996 and found that consumers subject to higher switching costs paid higher prices; and Grzybowski (2008), who found significant switching costs in the mobile sector in the United Kingdom after the turn of the century. Using a discrete choice experiment in a European country, Confraria et al. (2017) found that consumers were willing to pay 1.3 euros per month to shorten the lock-in period associated to their cellphone service from 12 to 6 months. Closer to our work, Shcherbakov (2016) studied switching costs in the TV industry in the United States between 1997 and 2006. Shcherbakov found that these costs amounted to $\$ 200$ and $\$ 244$ for cable and satellite systems, respectively. These estimates are close to the ones we find in our paper.

\section{Empirical Context}

We use an anonymized transactional dataset from a large telecommunications triple-play provider (hereinafter called TELCO) covering the period between April and October 2013. TELCO is a major provider of telecommunication services in the country that we analyze. The penetration of triple play service in this country is above $70 \%$, and in 2013 about $70 \%$ of TELCO customers subscribed triple-play service. The triple play service that TELCO provides includes TV, Internet and fixed telephony. For each household and each month, our dataset contains information on the services subscribed and prices charged. For each bundle of services offered by TELCO we have bundle-specific characteristics such as the number of TV channels, the maximum Internet speed, premium features (such as access to Video-onDemand), and whether mobile service was included. We also obtained information on the service bundles that were provided by TELCO competitors in the zip code where each household, served by TELCO, was located. We know how many providers offer each bundle and the lowest price charged for it.

Finally, this dataset includes household level covariates such as contract details, including the length of the lock-in period and the number of months that elapsed since the household subscribed each service, and information on the monthly usage of the services contracted, such as Internet traffic (uploads and downloads in megabytes) and the number of landline calls placed and received. We obtained data for a random sample of 100,000 triple-play households of which we discarded 2,772 for which information on the services contracted was unavailable.

Table 1 summarizes the service bundles that TELCO offered in 2013. They differ in the number of TV channels offered, Internet speeds and whether advanced features to watch TV were available. For example, bundles marked premium offered advanced features such as video-recording and Videoon-Demand. One bundle offered mobile service. This table reports the average price charged for each bundle alongside its standard deviation. The same bundle may be charged different prices to different households depending, for example, on when each household signed up, the negotiation between the household and the firm, and active marketing campaigns at the time of sign-up. 
Table 1. Summary Statistics for Triple-Play Service Bundles Offered by TELCO

\begin{tabular}{|c|c|c|c|c|c|c|c|c|c|}
\hline No. & Share & $\begin{array}{c}\text { No. } \\
\text { Channels }\end{array}$ & Internet & Telephony & Premium & Mobile & $\begin{array}{l}\text { Avg. } \\
\text { Price }\end{array}$ & $\begin{array}{l}\text { Std. } \\
\text { Price }\end{array}$ & $\begin{array}{l}\text { Best } \\
\text { Price }\end{array}$ \\
\hline 1 & 0.20 & $\simeq 120$ & $\simeq 30 \mathrm{mbps}$ & Yes & No & No & 57.62 & 13.42 & 52.59 \\
\hline 2 & 0.13 & $\geq 160$ & $\simeq 100 \mathrm{mbps}$ & Yes & Yes & No & 64.73 & 5.71 & 62.57 \\
\hline 3 & 0.12 & $\geq 160$ & $\simeq 100 \mathrm{mbps}$ & Yes & Yes & No & 71.65 & 12.36 & 67.75 \\
\hline 4 & 0.11 & $\geq 160$ & $\simeq 30 \mathrm{mbps}$ & Yes & Yes & No & 57.57 & 5.77 & 53.63 \\
\hline 5 & 0.07 & $\geq 160$ & $\simeq 100 \mathrm{mbps}$ & Yes & Yes & No & 73.41 & 4.04 & 69.51 \\
\hline 6 & 0.07 & $\geq 160$ & $\simeq 100 \mathrm{mbps}$ & Yes & Yes & No & 76.78 & 10.67 & 71.65 \\
\hline 7 & 0.05 & $\simeq 120$ & $\simeq 10 \mathrm{mbps}$ & Yes & No & No & 58.68 & 4.77 & 51.08 \\
\hline 8 & 0.04 & $\simeq 120$ & $\simeq 10 \mathrm{mbps}$ & Yes & No & No & 54.31 & 2.54 & 53.36 \\
\hline 9 & 0.04 & $\simeq 150$ & $\simeq 10 \mathrm{mbps}$ & Yes & No & No & 57.16 & 4.49 & 54.59 \\
\hline 10 & 0.03 & $\geq 160$ & $\simeq 100 \mathrm{mbps}$ & Yes & Yes & No & 73.01 & 12.10 & 70.50 \\
\hline 11 & 0.03 & $\simeq 150$ & $\simeq 100 \mathrm{mbps}$ & Yes & No & No & 54.98 & 11.46 & 52.92 \\
\hline 12 & 0.02 & $\simeq 30$ & $\simeq 10 \mathrm{mbps}$ & Yes & No & No & 51.99 & 0.10 & 51.99 \\
\hline 13 & 0.02 & $\simeq 30$ & $\simeq 1 \mathrm{mbps}$ & Yes & No & No & 45.93 & 1.23 & 45.48 \\
\hline 14 & 0.02 & $\geq 160$ & $\simeq 100 \mathrm{mbps}$ & Yes & Yes & Yes & 101.97 & 11.40 & 100.31 \\
\hline 15 & 0.02 & $\simeq 150$ & $\simeq 10 \mathrm{mbps}$ & Yes & No & No & 55.82 & 6.78 & 53.36 \\
\hline 16 & 0.02 & $\simeq 120$ & $\simeq 30 \mathrm{mbps}$ & Yes & No & No & 58.67 & 3.85 & 57.65 \\
\hline
\end{tabular}

Notes: All monetary values are in 2013 U.S. Dollars. Premium is a dummy variable indicating whether the product contains premium features. Best Price stands for the lowest introductory price available in the local market (zip code) for a bundle with similar features offered by other service providers.

The best price column in this table provides information on the lowest available introductory price for each bundle. This statistic was calculated based on the information available about the offers extended by TELCO's competitors in each household's zip code. During our period of analysis, the average number of service providers per zip code was 2.88 and the median was 3 .

During our period of analysis, consumers could change service bundle inside TELCO or churn. A consumer whose lockin period ends commits to a 12-month lock-in period when she changes service bundle inside TELCO. A consumer that is more than 12 months away from lock-in expiry experiences no change in the lock-in period when she changes service bundle inside TELCO. A consumer who is less than 12 months away from lock-in expiry gets her lock-in period reset to 12 months if she changes service bundle inside the carrier. New consumers always face a lock-in period of 24 months. If a consumer switches provider, then a lock-in period of 24 months is enforced by the new provider. Between April and October 2013, and on average per month, around 1\% of TELCO consumers churn, $4 \%$ change service bundle inside TELCO and $1 \%$ are new to TELCO.

Figure 1 shows the density of changes inside TELCO and churn as a function of time to lock-in expiry. The x-axis shows the number of months to lock-in expiry. Negative values indicate the number of months elapsed after the lock-in period expired. Rates of change in these figures are small within the first 12 months of a 24-month lock-in period. Otherwise, change happens once lock-in periods expire, in particular around month 24, when significant churn occurs. Sometimes, consumers churn when there is still 1 month to lock-in expiry because competitors cover this financial penalty to steal consumers from competitors (by offering consumers a few months of service for free). Changes of service bundle inside TELCO happen within the second half of a 24 month lock-in period. A peak of changes within TELCO occurs at around 10 months into the lock-in period, which may be related to TELCO's proactive marketing strategies that are, in part, aimed at ensuring that lock-in expiry remains far in the future. During our period of analysis, $54 \%$ of the households in our sample were within a lock-in period. Furthermore, during our period of analysis, all major service providers that compete with TELCO offered contracts similar to those offered by TELCO.

\section{Model}

We follow the approach laid out in Figure 2 to study the impact of changing lock-in periods on consumer surplus and 

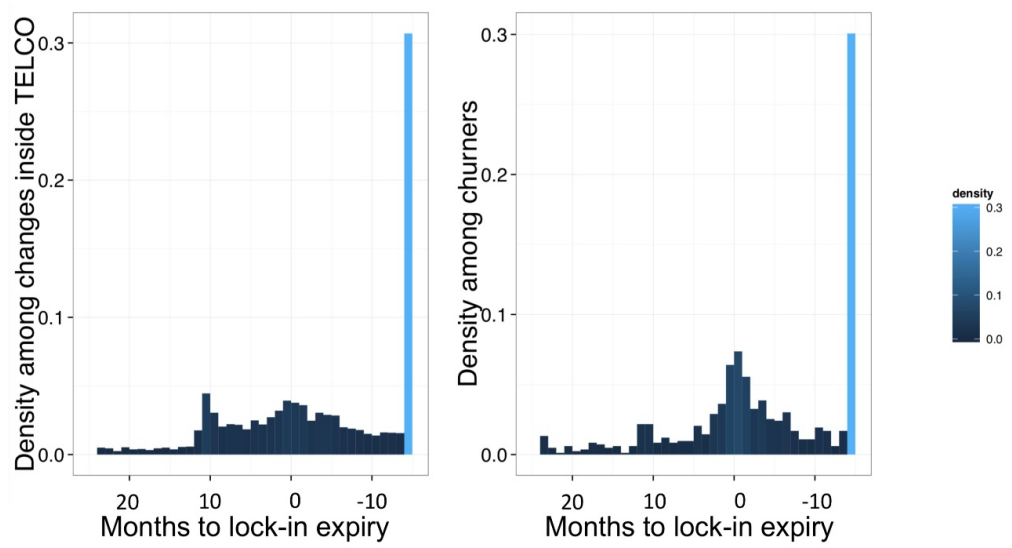

Figure 1. Density of Changes Inside TELCO and Churn as a Function of Time to Lock-in Expiry

Figure 2. Flowchart for our Policy Simulations

on firm profit. First, we use the dataset that TELCO provided us to estimate the demand for the different service bundles available to consumers at any point in time. We use discrete choice models to do so. Second, we use the results from these models to simulate churn rates and consumer surplus as a function of changes to the length of the lock-in period. Finally, firm profits are determined using the predicted market shares for the different products, their prices and the rates of churn predicted by our model, allowing us to compute revenue flows over the expected lifetime of consumers with TELCO.

In the next subsections we provide a detailed overview of how we model consumer behavior, firm profit, consumer surplus and welfare.

\section{The Consumers' Choice Model}

We model household behavior using a multinomial logit model. In this model, households choose among $J+2$ alternatives: triple play bundles at TELCO (denoted as options 1 through $J$ ), an option to downgrade service by choosing a non-triple-play bundle at TELCO, ${ }^{3}$ or churn (denoted by option $J+2$ ). When a household churns, we assume that she subscribes to a similar service bundle from a competitor at a lower price. The prices offered by competitors were described earlier. In this setting, the utility of household $h$ from choosing alternative $j$ at time $t$, represented by $u_{h j}^{t}$, is given by

$u_{h j}^{t}\left(X_{j}, p_{h j}^{t}, \boldsymbol{a}_{h}^{t-1}, z_{h}^{t}, l_{h}^{t}, L_{h j}^{t}\right)=V_{h j}^{t}\left(X_{j}, p_{h j}^{t}, \boldsymbol{a}_{h}^{t-1}, z_{h}^{t}, l_{h}^{t}, L_{h j}^{t}\right)+\varepsilon_{h j}^{t}$

where $V(*)$ represents the observable part of utility, which depends on a vector of bundle-specific characteristics $X_{j}$, the monthly bill $p_{h j}^{t}$, the houehold's choice of service bundles up to the previous time period $\boldsymbol{a}_{\boldsymbol{h}}^{t-1}=\left\{a_{h}^{1}, \ldots, a_{h}^{t-1}\right\}$ where $a_{h}^{\tau}$ represents the choice of household $h$ at time $\tau$, a vector of

\footnotetext{
${ }^{3}$ TELCO offered several non-triple play bundles during our period of analysis, namely "TV-only," "TV+Internet," and "TV+Voice," In our data, $0.9 \%$ of the triple play households move to such a bundle.
} 
demographic time-varying characteristics $z_{h}^{t}$, the remaining lock-in period $l_{h}^{t}$, and the original length of the last lock-in period (potentially the current one if still active) $L_{h j}^{t} \cdot \varepsilon_{h j}^{t}$ represents the idiosyncratic error term, which we assume follows an i.i.d. Type I extreme value distribution. The probability that household $h$ chooses alternative $j$ at time $t$, is given by

$$
\begin{aligned}
P\left(a_{h}^{t}\right. & \left.=j \mid\left\{X_{j}, p_{h j}^{t}, \boldsymbol{a}_{h}^{t-1}, z_{h}^{t}, l_{h}^{t}, L_{h j}^{t}\right\}_{j=1}^{J+2}\right) \\
& =\frac{\exp u_{h j}^{t}\left(X_{j}, p_{h j}^{t}, \boldsymbol{a}_{h}^{t-1}, z_{h}^{t}, l_{h}^{t}, L_{h j}^{t}\right)}{\sum_{k=1}^{J+2} \exp u_{h k}^{t}\left(X_{k}, p_{h k}^{t}, \boldsymbol{a}_{h}^{t-1}, z_{h}^{t}, l_{h}^{t}, L_{h k}^{t}\right)}
\end{aligned}
$$

We use a linear functional form for $V\left({ }^{*}\right)$ to estimate switching costs both to change bundle inside TELCO as well as to churn. For this purpose, we define

$$
\begin{aligned}
& V_{h j}^{t}\left(X_{j}, p_{h j}^{t}, a_{h}^{t-1}, z_{h}^{t}, l_{h}^{t}, L_{h j}^{t}\right)=X_{j} a-\beta p_{h j}^{t}+z_{h}^{t} \mu_{j} \\
& \quad-\gamma_{1} C_{h j}^{t} I_{j}+\gamma_{2} C_{h j}^{t} O_{j} 1\left(l_{h}^{t} \leq 1\right)+\gamma_{3} C_{h j}^{t} O_{j} 1\left(l_{h}^{t}>1\right) \\
& \quad+\gamma_{4} C_{h j}^{t} O_{j} 1\left(l_{h}^{t}>1\right) l_{h}^{t}+\gamma_{5} C_{h j}^{t} O_{j} 1\left(l_{h}^{t} \leq 1\right) L_{h j}^{t} \\
& \quad+\gamma_{6} C_{h j}^{t} O_{j} 1\left(l_{h}^{t}>1\right) L_{h j}^{t}+\gamma_{7} C_{h j}^{t} O_{j} 1\left(l_{h}^{t} \leq 1\right) \text { Tenure }_{h}^{t} \\
& \quad+\gamma_{8} C_{h j}^{t} O_{j} 1\left(l_{h}^{t} \leq 1\right) \text { Tenure }_{h}^{t}+\gamma_{9} C_{h j}^{t} I_{j} N_{h}^{t} \\
& \quad+\gamma_{10} C_{h j}^{t} O_{j} 1\left(l_{h}^{t} \leq 1\right) N_{h}^{t}+\gamma_{11} C_{h j}^{t} O_{j} 1\left(l_{h}^{t}>1\right) N_{h}^{t}
\end{aligned}
$$

where $I_{j}=1\left(j \neq\right.$ "churn") and $O_{j}=1(j=$ "churn") indicate whether alternative $j$ is a bundle inside TELCO or churn, respectively. $C_{h j}^{t}=1\left(a_{h}^{t-1} \neq j\right)$ indicates whether household $h$ changes service bundle at time $t$. Tenure $e_{h}^{t}$ indicates the tenure of household $h$ at time $t$ with TELCO and $z_{h}^{t} \mu_{j}$ represent interactions between household characteristics and dummies for each alternative. Additionally, $N_{h}^{t}$ represents the number of TELCO competitors in the zip code where household $h$ is located that offer a service similar to the one currently subscribed by household $h$. All coefficients in this expression have economic meaning and their ratios to $\beta$ provide interpretations in dollar terms. Table 2 describes these coefficients, their meaning, and the signs that we expect to observe empirically.

\section{Churn Rates, Consumer Surplus, and TELCO Profits}

Churn rates are determined by the market share of the churn alternative in the multinomial choice model introduced above. The consumer surplus of the representative household is determined by the utility provided by the best alternative available to her, that is

$$
\begin{gathered}
C S_{h}^{t}\left(\left\{\Gamma_{h j}^{t}, L_{h j}^{t}\right\}_{j=1}^{J+2}\right)=\frac{1}{\beta} \max _{j=1, \ldots, J+2}\left\{u_{h j}^{t}\left(\Gamma_{h j}^{t}, L_{h j}^{t}\right)\right\} \\
E\left[C S_{h}^{t}\left(\left\{\Gamma_{h j}^{t}, L_{h j}^{t}\right\}_{j=1}^{J+2}\right)\right]=\frac{1}{\beta} \ln \left(\sum_{j=1}^{J+2} \exp \left(V_{h j}^{t}\left(\Gamma_{h j}^{t}, L_{h j}^{t}\right)\right)\right)+C
\end{gathered}
$$

where, for the sake of space, $\Gamma_{h j}^{t}=\left(X_{j} p_{h j}^{t}, \boldsymbol{a}_{h}^{t-1}, z_{h}^{t}, l_{h}^{t}\right)$ and $h$ denotes the representative household. The approximation for the expected value is obtained from integrating over the distribution of the error term. In this model, $C$ is an unknown constant that is irrelevant for comparison purposes and therefore usually ignored for policy analysis (Train 2009). The expected cumulative surplus of the representative household is given by

$$
\begin{aligned}
& E\left[C S_{h}\left(\left\{\Gamma_{h j}^{t}, L_{h j}^{t}\right\}_{j=1}^{J+2}\right)\right]= \\
& \sum_{t=0}^{\infty} \frac{E\left[C S_{h}^{t}\left(\left\{\Gamma_{h j}^{t}, L_{h j}^{t}\right\}_{j=1}^{J+2}\right)\right]}{(1+\delta)^{t}} A_{h}^{t}\left(\left\{\Gamma_{h j}^{t}, L_{h j}^{t}\right\}_{j=1}^{J+2}\right) \\
& A_{h}^{t}\left(\left\{\Gamma_{h j}^{t}, L_{h j}^{t}\right\}_{j=1}^{J+2}\right)= \\
& \prod_{\tau=0}^{t-1} 1-P\left(a_{h}^{\tau}=\text { "churn"| }\left\{\Gamma_{h j}^{\tau}, L_{h j}^{\tau}\right\}_{j=1}^{J+2}\right)
\end{aligned}
$$

where $A_{h}^{t}(\bullet)$ represents the survival probability of household $h$ at time $t$ and $\delta$ represents this household's monthly discount rate.

TELCO profits are given by the difference between the discounted revenues obtained by providing service to the representative household and the cost to acquire and setting up its service. The latter is represented below by $A C_{T E L C O, h}$. These costs, incurred by TELCO at the beginning of each contract, include capital costs with equipment, such as Internet modems and set-top boxes, and costs to deploy it at the customer premises, which usually requires a visit from a specialized technician. The discounted future revenues of TELCO include expected revenues from providing service to the representative household, denoted below by $\Pi_{T E L C O, h, t}^{M P}$ for month $t$ and expected penalties collected when she terminates service before the lock-in period expires, denoted below by $\prod_{T E L C O, h, t}^{P e n}$ for month $t$, and are thus given by

$$
\begin{aligned}
& \prod_{T E L C O, h}\left(\left\{\Gamma_{h j}^{t}, L_{h j}^{t}\right\}_{j=1}^{J+2}\right)= \\
& \sum_{t=0}^{\infty} \frac{\Pi_{T E L C O, h, t}^{M P}\left(\left\{\Gamma_{h j}^{t}, L_{h j}^{t}\right\}_{j=1}^{J+2}\right)+\Pi_{T E L C O, h, t}^{P e n}\left(\left\{\Gamma_{h j}^{t}, L_{h j}^{t}\right\}_{j=1}^{J+2}\right)}{(1+r)^{t}} \\
& \quad-A C_{T E L C O, h}
\end{aligned}
$$




\begin{tabular}{|c|c|c|}
\hline Label & Interpretation & Hypothesis \\
\hline$\beta$ & Effect of price on product utility & Negative sign. Utility reduces with price. \\
\hline$\gamma_{1}$ & $\begin{array}{l}\text { Switching cost associated to changing bundle inside } \\
\text { TELCO. }\end{array}$ & $\begin{array}{l}\text { Negative sign. Switching costs negatively affect } \\
\text { utility. }\end{array}$ \\
\hline$\gamma_{2}$ & $\begin{array}{l}\text { Switching cost associated to churn when there is at } \\
\text { most } 1 \text { month to the end of the current lock-in period. }\end{array}$ & $\begin{array}{l}\text { Negative sign. Switching costs negatively affect } \\
\text { utility. }\end{array}$ \\
\hline$\gamma_{3}$ & $\begin{array}{l}\text { Switching cost associated to churn when there is } \\
\text { more than } 1 \text { month to the end of the current lock-in } \\
\text { period. }\end{array}$ & $\begin{array}{l}\text { Negative sign. Switching costs negatively affect } \\
\text { utility. }\end{array}$ \\
\hline$\gamma_{4}$ & $\begin{array}{l}\text { Change in } \gamma_{3} \text { with one more month of lock-in } \\
\text { remaining. }\end{array}$ & $\begin{array}{l}\text { Negative sign. The more months remaining in the } \\
\text { lock-in period the higher the switching cost. }\end{array}$ \\
\hline$\gamma_{5}$ & $\begin{array}{l}\text { How } \gamma_{2} \text { changes with the original length of the current } \\
\text { lock-in period. }\end{array}$ & $\begin{array}{l}\text { Positive sign. Consumers may get tired of a longer } \\
\text { contract and be more likely to churn when the } \\
\text { contract has expired. }\end{array}$ \\
\hline$\gamma_{6}$ & $\begin{array}{l}\text { How } \gamma_{3} \text { changes with the original length of the current } \\
\text { lock-in period. }\end{array}$ & No hypothesis made. \\
\hline$\gamma_{7}$ & How $\gamma_{2}$ changes with household tenure. & $\begin{array}{l}\text { Negative sign. Users with longer tenure are less } \\
\text { likely to churn. }\end{array}$ \\
\hline$\gamma_{8}$ & How $\gamma_{3}$ changes with household tenure. & $\begin{array}{l}\text { Negative sign. Users with longer tenure are less } \\
\text { likely to churn. }\end{array}$ \\
\hline$\gamma_{9}$ & $\begin{array}{l}\text { How } \gamma_{1} \text { changes with one more competitor in the } \\
\text { local market. }\end{array}$ & $\begin{array}{l}\text { Positive sign. More competition likely leads to less } \\
\text { switching costs. }\end{array}$ \\
\hline$\gamma_{10}$ & $\begin{array}{l}\text { How } \gamma_{2} \text { changes with one more competitor in the } \\
\text { local market. }\end{array}$ & $\begin{array}{l}\text { Positive sign. More competition likely leads to less } \\
\text { switching costs. }\end{array}$ \\
\hline$\gamma_{11}$ & $\begin{array}{l}\text { How } \gamma_{3} \text { changes with one more competitor in the } \\
\text { local market. }\end{array}$ & $\begin{array}{l}\text { Positive sign. More competition likely leads to less } \\
\text { switching costs. }\end{array}$ \\
\hline
\end{tabular}

where $r$ denotes TELCO's Rate of Return (RoR). TELCO's expected revenues from household in month are determined by

$$
\prod_{T E L C O, h, t}^{M P}\left(\left\{\Gamma_{h j}^{t}, L_{h j}^{t}\right\}_{j=1}^{J+2}\right)=\sum_{k=1}^{J+1} s_{k}^{t}\left(p_{h k}^{t}-c_{h k}^{t}\right) A_{h}^{t}\left(\left\{\Gamma_{h j}^{t}, L_{h j}^{t}\right\}_{j=1}^{J+2}\right)(9)
$$

where $s_{k}^{t}\left(a_{h}^{t}\right)=P\left(a_{h}^{t}=k\right)$ represents the market share (within TELCO) of alternative $k$ and $c_{h k}^{t}$ represents the marginal operational cost of this alternative for household $h$. Expected revenues from the financial penalties collected at month $t$ are determined by

$$
\begin{aligned}
& \Pi_{\text {TELCO,h,t }}^{\text {Pen }}\left(\left\{\Gamma_{h j}^{t}, L_{h j}^{t}\right\}_{j=1}^{J+2}\right)= \\
& \quad \sum_{k=1}^{J+1} s_{k}^{t-1} \mathbf{1}\left(L_{h j}^{t}-t \geq 1\right) p_{h k}^{t-1}\left(L_{h}^{t}-t\right) B_{h}^{t}\left(\left\{\Gamma_{h j}^{t}, L_{h j}^{t}\right\}_{j=1}^{J}\right)
\end{aligned}
$$

where $B_{h}^{t}(\bullet)$ denotes the probability of churn of household $h$ at time $t$ from TELCO, which is given by

$$
\begin{aligned}
& B_{h}^{t}\left(\left\{\Gamma_{h j}^{t}, L_{h j}^{t}\right\}_{j=1}^{J+2}\right)= \\
& P\left(a_{h}^{t}=\text { "churn" } \mid\left\{\Gamma_{h j}^{t}, L_{h j}^{t}\right\}_{j=1}^{J+2}\right) \\
& \prod_{\tau=0}^{\tau-1} 1-P\left(a_{h}^{\tau}=\text { "churn" } \mid\left\{\Gamma_{h j}^{\tau}, L_{h j}^{\tau}\right\}_{j=1}^{J+2}\right)
\end{aligned}
$$

\section{The Effect of Changing the Length of the Lock-in Period}

Throughout this section we assume that changes in the length of the lock-in period are applied to all service bundles and to every carrier in our market equally. This is a reasonable assumption given that the law governing lock-in periods is always a market level policy enforced by each country's National Regulatory Agency (or in the case of Europe by a Directive from the European Commission that each country's Government must transpose to national law). We also assume that, when a household churns due to a reduction in the lockin period, she subscribes to a service at a competitor in our 
market. This is a reasonable assumption in today's telecommunication markets because the level of household penetration of telecommunication services has remained unchanged in most developed countries for several years now (STATISTA 2017a, 2017b, 2017c). In particular, in the country that we analyze, roughly $90 \%$ of the households subscribe to telecommunications services for more than six years. In fact, we assume that when a household churns because the length of lock-in period shortens she subscribes a service at a competitor similar to the one she used to subscribe before she churned. This is a reasonable assumption in today's telecommunication markets because triple-play providers tend to compete by offering similar services.

Shortening the length of the lock-in period ( $L_{h j}^{t}$ ) by months (to $L_{h j}^{t}-m$ ) changes the monthly payments collected by TELCO, as well as the revenues associated to contract breaches. The change in TELCO's profit is therefore given by

$$
\begin{aligned}
& \Delta \prod_{T E L C O, h}\left(\left\{\Gamma_{h j}^{t}, L_{h j}^{t}\right\}_{j=1}^{J+2}, m\right)= \\
& \sum_{t=0}^{\infty} \frac{\Delta \prod_{T E L C O, h, t}^{M P P}\left(\left\{\Gamma_{h j}^{t}, L_{h j}^{t}\right\}_{j=1}^{J+2}, m\right)+\Delta \prod_{T E L C O, h, t}^{P e n}\left(\left\{\Gamma_{h j}^{t}, L_{h j}^{t}\right\}_{j=1}^{J+2}, m\right)}{(1+r)^{t}} \\
& \Delta \prod_{T E L C O, h, t}^{M P}\left(\left\{\Gamma_{h j}^{t}, L_{h j}^{t}\right\}_{j=1}^{J+2}, m\right)= \\
& \prod_{T E L C O, h, t}^{M P}\left(\left\{\Gamma_{h j}^{t}, L_{h j}^{t}\right\}_{j=1}^{J+2}\right)-\prod_{T E L C O, h, t}^{P e n}\left(\left\{\Gamma_{h j}^{t}, L_{h j}^{t}-m\right\}_{j=1}^{J+2}\right) \\
& \Delta \prod_{T E L C O, h, t}^{P e n}\left(\left\{\Gamma_{h j}^{t}, L_{h j}^{t}\right\}_{j=1}^{J+2}, m\right)= \\
& \prod_{T E L C O, h, t}^{P e n}\left(\left\{\Gamma_{h j}^{t}, L_{h j}^{t}\right\}_{j=1}^{J+2}\right)-\prod_{T E L C O, h, t}^{P e n}\left(\left\{\Gamma_{h j}^{t}, L_{h j}^{t}-m\right\}_{j=1}^{J+2}\right)
\end{aligned}
$$

Households are likely to churn earlier when the length of the lock-in period shortens. Therefore, both $\Delta \prod_{T E L C O, h, t}^{M P}$ and $\Delta \prod_{T E L C O, h, t}^{P e n}$ are negative in this model. Let $f$ represent the firm (TELCO's competitor) capturing a household that churns from TELCO. When the length of the lock-in period shortens by months the profits of firm $f$ from household $h$ changes according to

$$
\begin{aligned}
& \Delta \Pi_{f, h}\left(\left\{\Gamma_{h j}^{t}, L_{h j}^{t}\right\}_{j=1}^{J+2}, m\right)= \\
& \quad-\sum_{t=0}^{\infty} \frac{\Delta \prod_{f, h, t}^{M P}\left(\left\{\Gamma_{h j}^{t}, L_{h j}^{t}\right\}_{j=1}^{J+2}, m\right)+\Delta \prod_{f, h, t}^{P e n}\left(\left\{\Gamma_{h j}^{t}, L_{h j}^{t}\right\}_{j=1}^{J+2}, m\right)}{(1+r)^{t}} \\
& \quad-\Delta A C_{f, h}
\end{aligned}
$$

where the minus sign denotes the fact that, contrary to TELCO, firm $f$ captures, instead of loses, household $h$. Note that, in this case, firm $f$ incurs $A C_{f, h}$ when household $h$ churns because she needs to set up service for her (TELCO does not incur this cost because it loses, instead of acquires, household h). We compute what happens at the market level by adding up expression 12 to expression 15, which together allow us to determine what happens to the profits of the firms when the length of the lock-in period reduces, and to expression 16 below, which determines how shortening the length of the lock-in period by $m$ months changes the consumer surplus of the representative household:

$$
\begin{aligned}
& E\left[C S_{h}\left(\left\{\Gamma_{h j}^{t}, L_{h j}^{t}\right\}_{j=1}^{J+2}, m\right)\right]= \\
& \quad E\left[C S_{h}\left(\left\{\Gamma_{h j}^{t}, L_{h j}^{t}\right\}_{j=1}^{J+2}\right)\right]-E\left[C S_{h}\left(\left\{\Gamma_{h j}^{t}, L_{h j}^{t}-m\right\}_{j=1}^{J+2}\right)\right]
\end{aligned}
$$

Finally, to build some intuition about how shortening lock-in periods may affect market welfare, consider a household that does not churn from TELCO because the length of the lock-in period shortens (from $L_{h j}^{t}$ to $L_{h j}^{t}-m$ ). In this case, both $\Delta \prod_{T E L C O, h, t}^{M P}$ and $\Delta \prod_{f, h, t}^{M P}$ are zero, and thus this household's willingness to pay for service at TELCO increases only because with a shorter lock-in period she can churn earlier from TELCO without paying a financial penalty. Consider now a household $h$ that churns from TELCO because the length of the lock-in period shortens. Assuming that such a household subscribes to a service at firm $f$ similar to the service that she used to subscribe at TELCO before she churned implies that $\triangle \prod_{T E L C O, h, t}^{M P}$ is similar to and $\Delta \prod_{f, h, t}^{M P}$ thus these terms roughly cancel out at the market level. Furthermore, this assumption also implies that this household's willingness to pay for this service at firm $f$ must be roughly similar to her willingness to pay for the service that she used to subscribe at TELCO, before the length of lock-in period changed, except for the fact that now with a shorter lock-in period she can churn earlier from TELCO without paying a financial penalty. Concerning costs, firm $f$ incurs the acquisition and setup cost when household $h$ churns $\left(A C_{f, h}\right)$. Therefore, the difference between the increase in the households' willingness to pay for service because the length of the lock-in period shortens (which allows them to churn earlier without paying a financial penalty) and the cost to acquire and set up service for the households that churn because the length of the lock-in period shortens determines the change in welfare triggered by shortening the lock-in period, which we compute later in our simulations to evaluate the effect of the policy at the market level. 


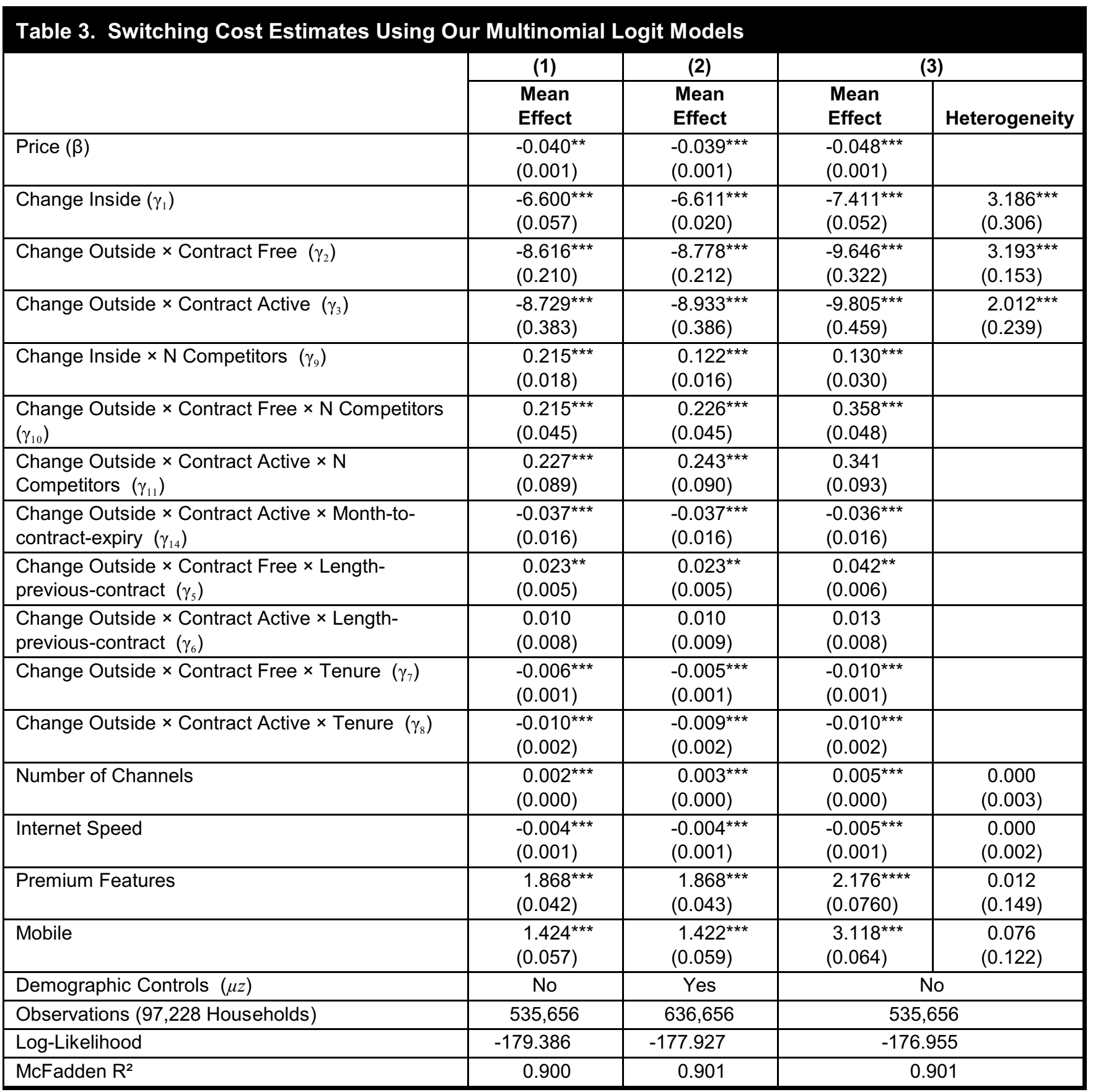

Notes: $p<0.01 ;{ }^{*} p<0.05 ;{ }^{* *} p<0.01 ;{ }^{* *} p<0.001$. Standard errors were robust clustered within households.

\section{Switching Costs Estimates}

Table 3 shows the empirical results obtained by applying the multinomial logit model described in the previous section to our dataset. Column (1) corresponds to equation (3) while columns (2) and (3) provide robustness checks. As expected, $\gamma_{1}, \gamma_{2}$, and $\gamma_{3}$ are all negative, indicating that switching costs reduce the probability of switching. The results in column (1) show that in a market with two service providers (TELCO and one competitor), if the lock-in period is over, the average switching cost associated to churn is \$210.1 ((-8.62+ $0.215) /-0.04)$. Furthermore, this statistic reduces by $\$ 5.4$ $(0.215 /-0.04)$ per additional competitor in the market. In the last month of the lock-in period, the average switching cost to 
churn is $\$ 212.6((-8.73+0.227) /-0.04)$. This statistic reduces by $\$ 5.7(0.227 /-0.04)$ per additional competitor and increases by $\$ 0.95(-0.037 /-0.040)$ per additional month outstanding in an active lock-in period. The average switching cost to change service bundle inside TELCO in a market with two service providers is $\$ 161.9((-6.60+0.122) /-0.04)$. In this case, one more competitor reduces this statistic by $\$ 3.1$ $(0.122 /-0.04)$.

Column (2) interacts household demographic characteristics (standardized) with product dummies to control for potential demographic effects. The demographic variables available to us are the age of the account holder and the household's intensity of usage for Internet and voice services. All estimates in this column are quantitatively similar to those shown in column (1). Finally, column (3) provides a model-based check for the assumption of independence of irrelevant alternatives (IIA) that is implicit in multinomial logit models (Keane 1992). We compare our results using the multinomial logit model to those obtained using a mixed logit model which does not impose IIA (Cheng and Long 2007). The results in column (3) are qualitatively similar to those reported in columns (1) and (2), thus providing strong evidence that the models in these columns are unlikely to violate the IIA assumption. Therefore, we rely on the model in column (1) to carry out our policy simulations in the next section, given that this model is computationally tractable while the mixed logit is not.

\section{Policy Simulations}

We now study how shortening the length of the lock-in period changes consumer behavior and thus affects market outcomes. We measure expected profits and consumer surplus using the expressions introduced earlier and we show how these statistics change relative to the status quo of 24-month lock-in periods. We use $\$ 390$ (in 2013 USD) as the average cost incurred by firms in our market to acquire consumers and set up service $\left(A C_{f, h}\right.$ in our model). This statistic, provided to us by TELCO, includes the cost of the equipment installed at that consumer premises and the cost associated with the trip of the technical team to the customer premises to install and activate the service. Appendix A summarizes the changes in churn rates that we obtain when we use the multinomial choice model introduced earlier to simulate what happens when the length of the lock-in period changes.

\section{Simulation Results with Prices Unchanged}

Figure 3 shows the results that we obtain from our first set of simulations in which we assume that firms do not change prices when the length of the lock-in period shortens. The top left plot shows $\triangle \Pi_{T E L C O, h}^{M P}$ as a function of the shortening of the lock-in period. Likewise, for the top right plot with respect to $\triangle \Pi_{T E L C O, h}^{P e n}$. The bottom left plot adds the former two plots, thus reporting $\Delta \Pi_{T E L C O, h}$, and the bottom right plot shows $\Delta \mathrm{E}\left[C S_{h}\right]$ as a function of the shortening of the lock-in period. This figure shows TELCO's profits using three different levels for the yearly rate of return (RoR), which were set around the typical rates experienced in the telecommunication sector $(9 \%, 11 \%$, and $13 \%$ according to data from Damodaran 2015). Consumer surplus is also computed using three different levels of discount rates. In this case, we surveyed the literature to determine how much households discount the future when they decide to subscribe to services similar to triple-play, which lead to selected discount rates ranging from 0.075 to $3.76{ }^{4}$

These simulations show that, when firms do not change prices, shortening the length of the lock-in period reduces TELCO's profits and increases consumer surplus. For example, in a market with TELCO and three additional service providers, when the lock-in period is shortened to 16 months, the present value of the expected consumer surplus for the representative household increases \$2 \$22, depending on the consumer discount rate. The net present value of the expected profits that TELCO enjoys from such a household reduces more than $\$ 50$. This loss in profit amounts to $1.5 \%$ of the expected present value of the profits that TELCO would obtain if the length of the lock-in period remained at 24 months. The results that we obtain for TELCO profits are qualitatively similar for different rates of return. As for consumer surplus, higher discount factors are associated with smaller changes in expected consumer surplus, when the length of the lock-in period shortens, because the future benefits that consumers obtain from such a reduction become substantially attenuated.

Figure 4 shows how shortening the length of the lock-in period affects profits and welfare at the market level. The plot on the left shows the former, that is, $\Delta \Pi_{T E L C O, h}+\Delta \Pi_{f, h}$, and the plot on the right shows the latter, that is, the former plus $\Delta \mathrm{E}\left[C S_{h}\right]$. Our results show that (on aggregate) firms

\footnotetext{
${ }^{4}$ In a very influential paper, Hausman (1979) found that consumers exhibit a discount rate of about $20 \% /$ year for energy-using durable goods. More recently, Yao et al. (2012), using cellphone data from China, reported discount factors between 10\%/year and 16\%/year (recall that discount factor $=$ $1 /(1+$ discount rate). In light of these estimates, we show results for yearly discount rates between 0.075 and 3.762 (corresponding to discount factors between 0.93 and 0.21 ).
} 

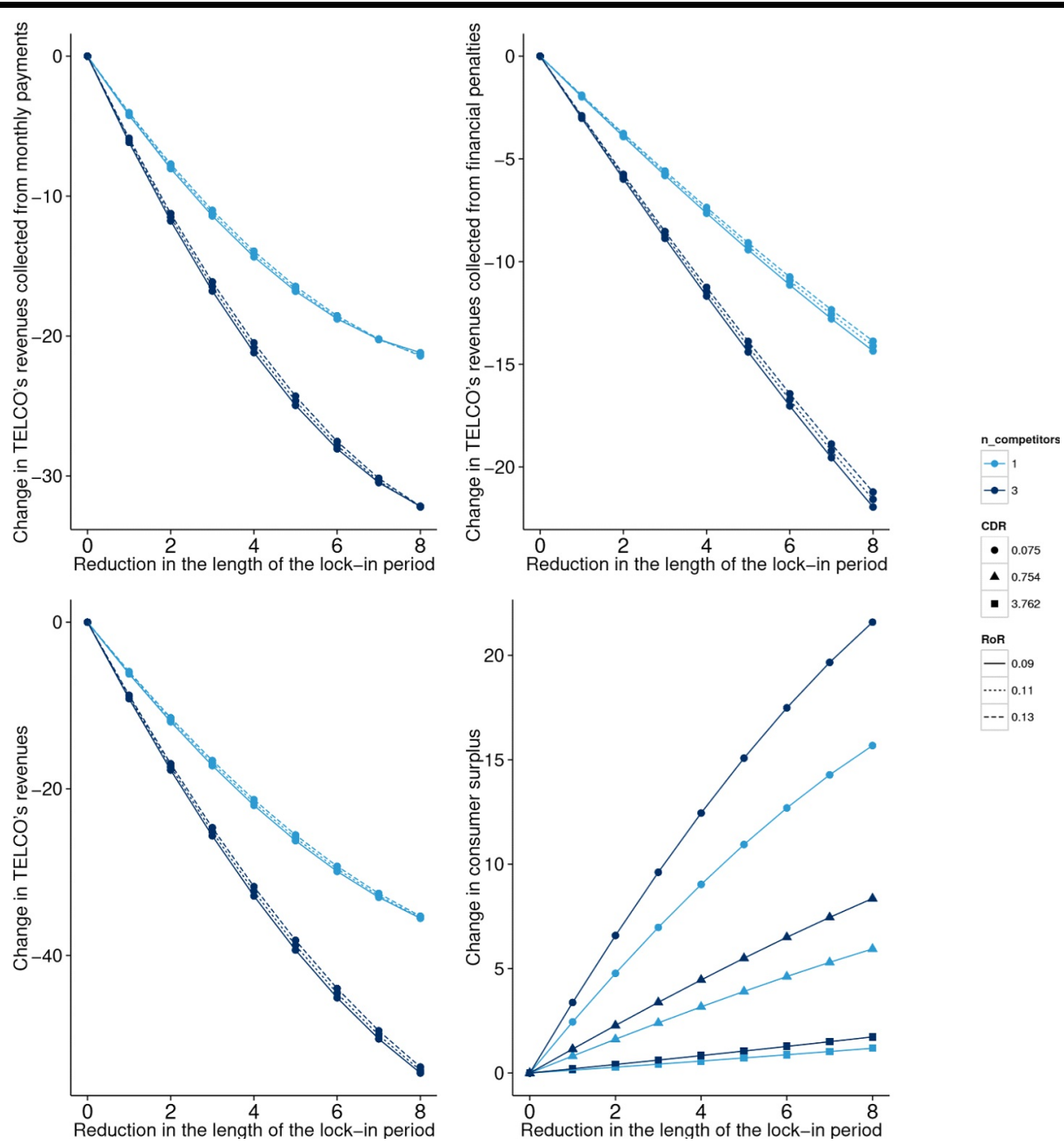

The change in TELCO's revenues collected from the representative household through monthly payments (top left) and breaching penalties (top right) as function of the reduction in the length of the lock-in period relative to the status quo of 24 months. The change in TELCO's total revenues from this household (bottom left) and the change in the consumer surplus (bottom right) as a function of the reduction in the length of the lock-in period relative to the status quo of 24 months. The results shown are for when TELCO faces one and three competitors, for different consumer discount rates (CDR) and different rates of return (RoR). Plots are based on simulations using the estimation results in column (1) of Table 3.

\section{Figure 3. Change in TELCO's Revenues}



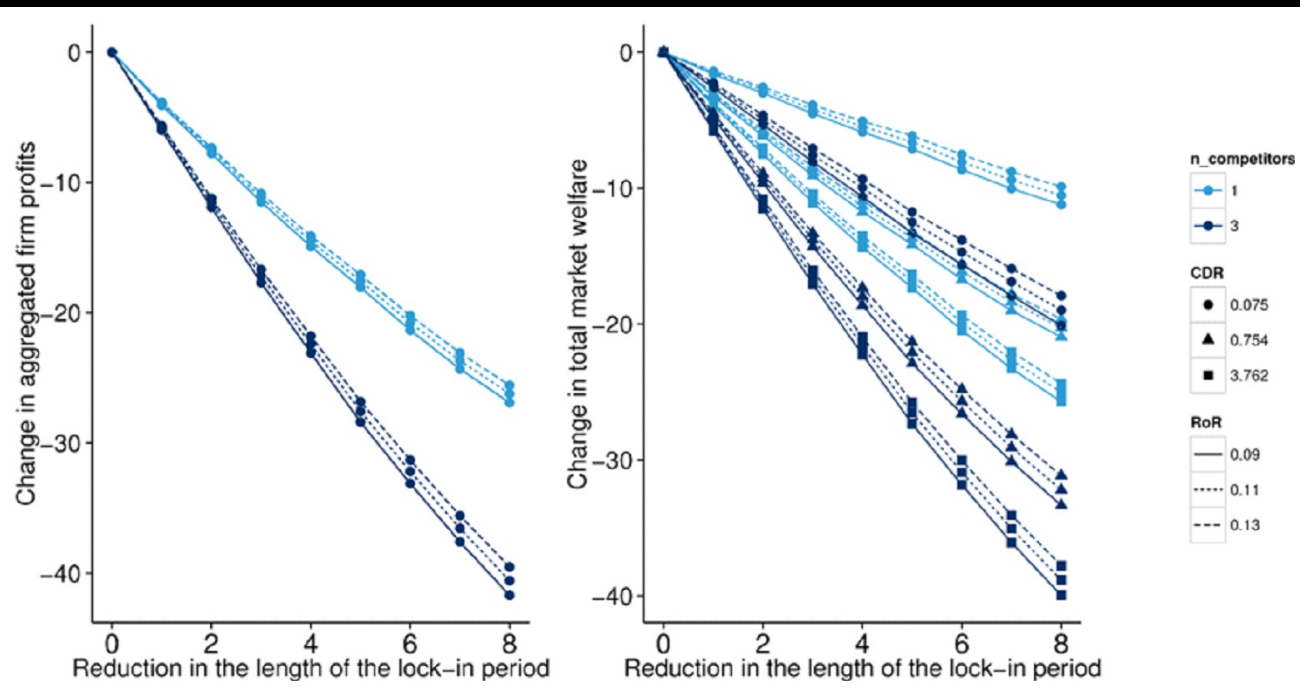

The change in aggregated firm profits (left) and in market welfare (right) as a function of the reduction in the length of the lock-in period from the status quo of 24 months. Results shown for when TELCO faces one and three competitors, for different CDR and different RoR. Plots are based on simulations using the estimation results in column (1) of Table 3.

\section{Figure 4. Change in Aggregated Firm Profits and Market Welfare}

lose more profit than what consumers gain in surplus when the length of the lock-in period shortens. For example, in a market with TELCO and three additional service providers, when the lock-in period is shortened to 16 months, the net present value of the aggregated expected profits reduces more than $\$ 40$, which supersedes the increase in the present value of the consumer surplus of the representative household (\$2 \$22, as indicated above). Using the intuition laid out earlier, this means that the costs incurred by firms to set up the households that churn because the length of the lock-in period shortens supersede the increase in the households' willingness to pay for service associated to the fact that the length of the lock-in period shortens. This figure also shows that these results remain unchanged for different consumer discount rates as well as for different rates of return.

\section{Consumer Surplus When Firms Increase Prices}

Our second set of simulations shows what happens if all firms increase prices similarly to compensate for the loss in profit due to the shortening of the lock-in period enforced by the NRA, a phenomenon similar to the "waterbed" effect observed in telephony (Genakos and Valletti 2011). A "waterbed" effect may also arise in triple play markets because these markets include only a few firms who can strategically inter- act with each other. ${ }^{5}$ In addition, in this set of simulations, and for sake of simplicity, we assume that firms increase the prices of all products by the same percentage points to keep their level of profitability (RoR). Figure 5 depicts the results that we obtain and shows that consumers are worse off when the length of the lock-in period shortens if firms react by increasing prices to keep their profitability. For example, in a market with TELCO and three other competitors, the plot on the left shows that firms increase prices by roughly $1.5 \%$ to counter the loss in profit that arises when the length of the lock-in period shortens by 8 months. The plot on the right shows that, in this case, consumer surplus reduces $\$ 4 \sim \$ 15$ depending on the discount rate. Therefore, consumers would have been better off if the NRA did not shorten the length of the lock-in period without preventing firms from increasing prices to counter the effect of such a policy on their profits. These results are similar for different consumer discount rates and for different rates of return for the firms, thus showing how shortening the lock-in period must be paired with price regulation, otherwise firms are likely to increase prices hurting consumers relative to the status quo of 24 -month lockin periods.

\footnotetext{
${ }^{5}$ If a market comprises only a few firms, the elasticity of the demand faced by one firm depends highly on the output of the other firms. Therefore, in this case, every firm has an incentive to coordinate and signal her behavior to the other firms.
} 

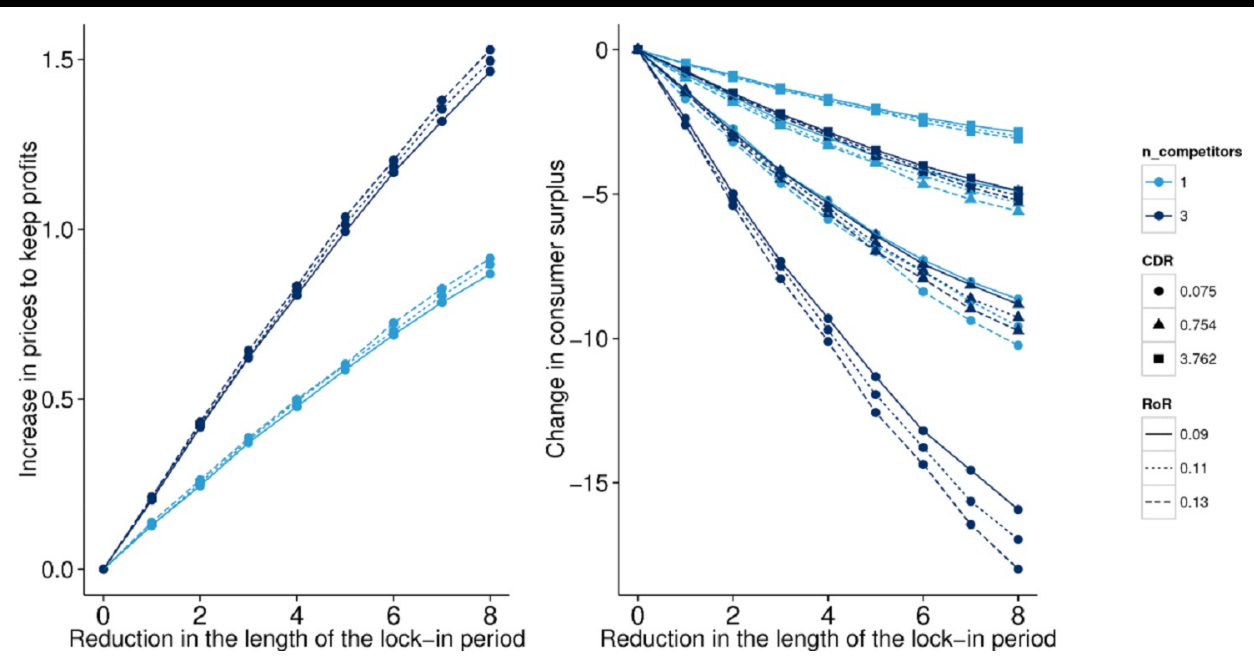

The percentage change in prices (left) and corresponding changes in consumer surplus (right) as a function of the reduction in the length of the lock-in period when firms increase prices to keep their profits relative to the status quo of 24-month lock-in periods. Results shown for when TELCO faces one and three competitors, for different CDR and RoR. Plots are based on simulations using the estimation results in column (1) of Table 3.

Figure 5. Percentage Change in Prices and Corresponding Changes in Consumer Surplus

\section{Simulation Results with Reduced Prices}

Our third set of simulations shows what happens when firms react to the shortening of the lock-in period by reducing prices. This may happen, for example, because shorter lockin periods allow consumers to churn more easily and thus firms may want to reduce prices to keep existing consumers. Then, when one firm reduces prices her competitors may also do so in response.

Figure 6 shows our results for when the lock-in period shortens from 24 to 16 months. As before, we assume that all firms discount the price of all products by the same percentage points. Our results show that when the firm's RoR and the consumer's discount rate are comparable, the price reduction changes firm profits and consumer surplus similarly, thus leaving the total market welfare roughly unchanged. However, when firms discount the future less than consumers, which is usually what happens in the telecommunication sector (Yao et al. 2012), again firms lose more profit than consumers gain surplus. This result provides additional robustness to our previous finding. The total welfare in the market decreases when the length of the lock-in period shortens, irrespective of whether firms react by increasing or decreasing prices. Finally, Figure $\mathrm{C} 1$ in Appendix $\mathrm{C}$ shows that results are similar when the lock-in period is shortened by less than 8 months, again providing additional robustness to our findings.

\section{Conclusions}

Lock-in periods in telecommunications services are a common practice employed by telecommunication providers to ensure that they cover the significant capital costs associated with building the network in the first place and to upgrade it over time. In short, operational revenues need to cover all operational costs and all investments in network upgrades, as well as the initial cost to set up the network. The current practice in the industry is to lock-in consumers for periods of 24 months, which reduces uncertainty for the firm. Consumers pay financial penalties if they breach contracts while lock-in periods are still active. These penalties are set up by firms in ways that ensure that they still cover the costs mentioned above even when consumers leave early.

Telecommunication regulators have been studying the effect of lock-in periods on consumer welfare to regulate them. Lock-in periods are a particular case of switching costs, and thus they may hurt consumers because they reduce their freedom to change telecommunications provider. In line with this reasoning, regulators have been shortening the length of lockin periods since the early 2000s and heated debate has recently ensued, once again, in several countries about reducing them further. Our paper uses a dataset from a large triple-play telecommunications provider to study what happens to consumers and to firms when the length of the lock-in period is shortened from the current status quo of 24 months. We find that on aggregate firms lose more profit than what 

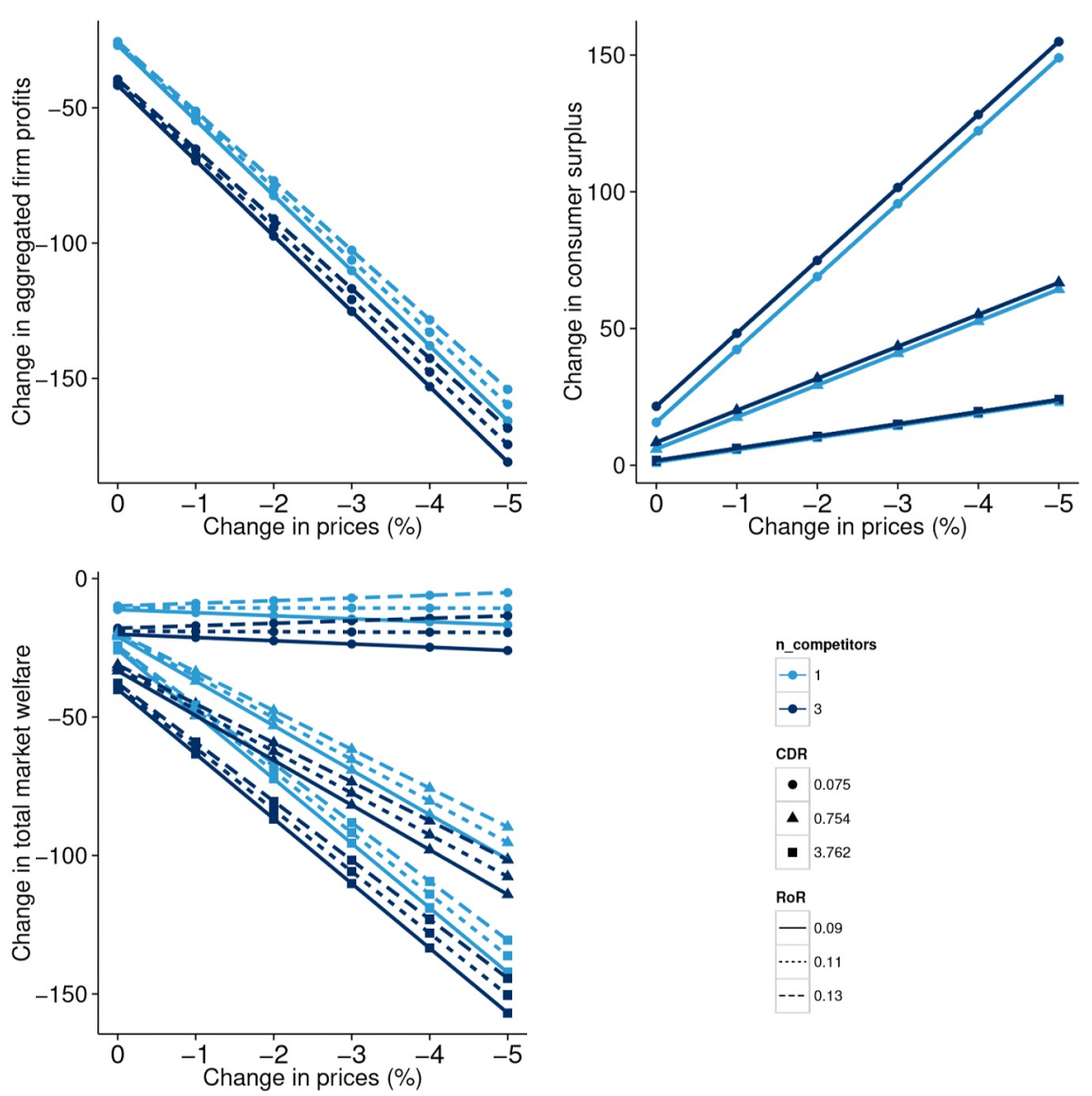

Effect of price decreases on aggregated firm profit (top left), consumer surplus (top right), and total market welfare (bottom left) when the lock-in period is shortened from 24 months to 16 months. Results show when TELCO faces one and three competitors, for different CDC and different RoR. Plots are based on simulations using the estimation results in column (1) of Table 3.

Figure 6. Effect of Price Decreases on Aggregated Firm Profit, Consumer Surplus, and Total Market Welfare

consumers gain in surplus when the length of lock-in periods shortens. This result shows that the costs associated to set up service for the households that churn due to the shorter lock-in period supersedes the increase in the consumers' willingness to pay for service associated to enjoying a shorter lock-in period (allowing consumers to churn earlier without paying a financial penalty). In practice, shortening the lock-in period increases churn and firms incur this cost more often. Furthermore, the cost to set up triple play service to a new consumer is far from trivial.

Our study also suggests that shortening the lock-in periods may be insufficient to improve consumer well-being. Specifically, our results show that consumers become worse-off if firms react to a policy that shortens the lock-in periods by increasing prices. This is possible because telecommunication markets have few firms that compete locally for many buyers, there are significant barriers to entry for firms and each firm's actions have large effect on the profitability of its rivals. We note that our results do not imply that regulators should not shorten the lock in periods, but they highlight that regulators need to ponder between the potential increase in consumer surplus from shortening the locking period against the additional costs that firms incur to set up the consumers that churn.

Finally, we note that our paper has several limitations. First, we do not study what could happen if NRAs extended, instead of shortened, the lock-in periods from the current status quo of 24 months. We only observe consumers locked-in for less than 24 months in our data, thus projecting what could happen with lock-in periods beyond 24 months would be extrapo- 
lating results outside the support of our data, an exercise of which we cannot be confident. In any case, studying how longer lock-in periods affect consumers and firms may be an object of future research. Second, our results are likely to generalize only to markets similar to the one that we empirically study in this paper, that is, markets where firms offer homogeneous products, lock-in consumers for relatively long periods of time and where the cost to acquire consumers and set up service is not trivial. Examples of such markets include broadband and cable, wireless, security and surveillance, and other utilities such as energy, gas and water. Third, our simulations assume that when a consumer churns because the length of the lock-in period shortens she signs up for a similar service from a competitor in the same market. This might not be the case in all markets, such as cellphone service, where consumers may churn to upgrade their service.

\section{Acknowledgments}

Miguel Godinho de Matos and Baojiang Yang were supported by the Portuguese Foundation for Science and Technology (Grants UID/GES/00407/2013 and PTDC/EGE-OGE/27968/2017). Baojiang Yang was supported by the Carnegie Mellon Portugal Program through the Portuguese Foundation for Science and Technology through Grant SFRH/BD/52611/2014. The authors thank António Moreira for excellent research assistantship. The authors thank Rodrigo Belo and Filipa Reis for valuable comments on earlier versions of this paper; the industry partner for their support; and the organizers of and participants in Workshop on the Economics of Network Industries in Paris and Workshop on Information Technologies and Systems in Dallas.

\section{References}

Bijwaard, G. E., Janssen, M. C., and Maasland, E. 2008. "Early Mover Advantages: An Empirical Analysis of European Mobile Phone Markets," Telecommunications Policy (32:3), pp. 246-261.

Borenstein, S. 1991. "Selling Costs and Switching Costs: Explaining Retail Gasoline Margins," The RAND Journal of Economics (22:3), pp. 354-369.

Cabral, L. 2009. "Small Switching Costs Lead to Lower Prices," Journal of Marketing Research (46:4), pp. 449-451.

Capgemini. 2009. "Quest for Margins: Operational Cost Strategies for Mobile Operators in Europe," Telecom \& Media Insights (42).

Cheng, S., and Long, J. S. 2007. "Testing for IIA in the Multinomial Logit Model," Sociological Methods \& Research (35:4), pp. 583-600.

Confraria, J., Ribeiro, T., and Vasconcelos, H. 2017. "Analysis of Consumer Preferences for Mobile Telecom Plans Using a Discrete Choice Experiment," Telecommunications Policy (41:3), pp. 157-169.
Congress. 2013. "Unlocking Consumer Choice and Wireless Competition Act," $113^{\text {th }}$ Congress (https://www.congress.gov/ bill/113th-congress/ house-bill/1123).

CRTC. 2012. "Proceeding to Establish a Mandatory Code for Mobile Wireless Services: Telecom Notice of Consultation CRTC 2012-557-1," Canadian Radio-television and Telecommunications Commission (https://crtc.gc.ca/eng/archive/2012/ 2012-557-1.htm).

CRTC. 2013. "The Wireless Code," Canadian Radio-television and Telecommunications Commission (https://crtc.gc.ca/eng/archive/ 2013/2013-271.htm).

Damodaran, A. 2015. "Cost of Capital Data by Sectors" (http:// www.stern.nyu.edu/ adamodar/New_Home_Page/data.html).

Doganoglu, T. 2010. "Switching Costs, Experience Goods and Dynamic Price Competition," Quantitative Marketing and Economics (8:2), pp. 167-205.

Dubé, J.-P., Hitsch, G. J., and Rossi, P. E. 2009. "Do Switching Costs Make Markets Less Competitive?," Journal of Marketing Research (46:4), pp. 435-445.

Epling, N. 2002. "Price Discrimination Amid Heterogeneous Switching Costs: A Competitive Tactic of the Telephony Resale Fringe," unpublished paper, Yale University.

European Union. 2009. "Regulatory Framework for Electronic Communications" (https://eur-lex.europa.eu/legal-content/EN/ TXT/?uri=LEGISSUM\%3Al24216a; updated September 30, 2015).

Farrell, J., and Klemperer, P. 2007. "Coordination and Lock-in: Competition with Switching Costs and Network Effects," Chapter 31 in Handbook of Industrial Organization (Volume 3), R. Schmalensee and R. Willig (eds.), Amsterdam: Elsevier, pp. 1967-2072.

Gans, J. S. 2001. "Regulating Private Infrastructure Investment: Optimal Pricing for Access to Essential Facilities," Journal of Regulatory Economics (20:2), pp. 167-189.

Genakos, C., and Valletti, T. 2011. "Testing the Waterbed Effect in Mobile Telephony," Journal of the European Economic Association (9:6), pp. 1114-1142.

Grzybowski, L. 2008. "Estimating Switching Costs in Mobile Telephony in the UK," Journal of Industry, Competition and Trade (8:2), pp. 113-132.

Hausman, J. A. 1979. "Individual Discount Rates and the Purchase and Utilization of Energy-Using Durables," The Bell Journal of Economics (10:1), pp. 33-54.

Keane, M. P. 1992. "A Note on Identification in the Multinomial Probit Model," Journal of Business \& Economic Statistics (10:2), pp. 193-200.

Klemperer, P. 1987. "Markets with Consumer Switching Costs," The Quarterly Journal of Economics (102:2), pp. 375-394.

Klemperer, P. 1995. "Competition When Consumers Have Switching Costs: An Overview with Applications to Industrial Organization, Macroeconomics, and International Trade," The Review of Economic Studies (62:4), pp. 515-539.

Knittel, C. R. 1997. "Interstate Long-Distance Rates: Search Costs, Switching Costs, and Market Power," Review of Industrial Organization (12:4), pp. 519-536. 
Lieberman, M. B., and Montgomery, D. B. 1998. "First-Mover (Dis) Advantages: Retrospective and Link with the ResourceBased View," Strategic Management Journal (30:2), pp. 1111-1125.

OVUM. 2015. "Telecoms, Media, \& Entertainment Outlook 2015" (https://www.scribd.com/document/273482459/OvumTelecoms-Media-and-Entertainment-Outlook-2015).

Sharpe, S. A. 1997. "The Effect of Consumer Switching Costs on Prices: A Theory and its Application to the Bank Deposit Market," Review of Industrial Organization (12:1), pp. 79-94.

Shcherbakov, O. 2016. "Measuring Consumer Switching Costs in the Television Industry," The RAND Journal of Economics (47:2), pp. 366-393.

Shin, J., and Sudhir, K. 2009. "Switching Costs and Market Competitiveness: Deconstructing the Relationship," Journal of Marketing Research (46:4), pp. 446-449.

Shy, O. 2002. "A Quick-and-Easy Method for Estimating Switching Costs," International Journal of Industrial Organization (20:1), pp. 71-87.

Stango, V. 2002. "Pricing with Consumer Switching Costs: Evidence from the Credit Card Market," The Journal of Industrial Economics (50:4), pp. 475-492.

STATISTA. 2017a. "Share of Households with Internet Access in the United Kingdom (UK) and the European Union (EU28) from 2007 to 2016" (https://www.statista.com/statisticsl275043/ percentage-of-households-with-internet).

STATISTA. 2017b. "Number of TV Households in Europe from 2009 to 2016 (in Million Households)" (https://www.statista. com/statistics/370199/households-with-a-televison-in-europe/).

STATISTA. 2017c. "Countries with the Highest Pay TV Penetration Rate in Europe in 2015" (https://www.statista.com/ statistics/307031/pay-tv-penetration-europe-country/).

Train, K. E. 2009. Discrete Choice Methods with Simulation (Volume 8), Cambridge, UK: Cambridge University Press.

Viard, V. B. 2007. "Do Switching Costs Make Markets More or Less Competitive? The Case of 800 -Number Portability," The RAND Journal of Economics (38:1), pp. 146-163.

Villas-Boas, J. M. 2015. "A Short Survey on Switching Costs and Dynamic Competition," International Journal of Research in Marketing (32:2), pp. 219-222.

Yao, S., Mela, C. F., Chiang, J., and Chen, Y. 2012. "Determining Consumers' Discount Rates with Field Studies," Journal of Marketing Research (49:6), pp. 822-841.

\section{About the Authors}

Baojiang Yang received a Ph.D. in Engineering and Public Policy from Carnegie Mellon University with a focus on information system and telecommunication policy. He also holds a master's degree in Electrical Engineering and Computer Science from Northwestern University and a bachelor's degree in Automation from Shanghai Jiaotong University. Baojiang's work focuses on leveraging econometrics and machine learning techniques to understand consumer decision making, companies' managerial strategies, and social influences in digital marketplaces.

Miguel Godinho de Matos received a Ph.D. in Engineering and Public Policy with focus on Telecommunications Policy and Management and a M.Sc. in Engineering and Public Policy from Carnegie Mellon University. Miguel also holds a M.Sc. and B.Sc. in Computer Engineering from Instituto Superior Técnico in Lisbon. Miguel's research interests focus on the analysis of digitization, social networks, and peer influence on consumer behavior and consumer choice. Miguel's work has been published in top journals such as Management Science, Marketing Science, MIS Quarterly, and Journal of Management Information Systems as well as in top peer-reviewed research conferences such as the International Conference on Information Systems and the Economics of Digitization Seminar Series of the National Bureau of Economic Research.

Pedro Ferreira's work focuses on how people use technology to consume experience goods and influence others to do so. These are inextricably linked to how firms behave and how public policies affect market structures. Pedro's work focuses on the application of robust empirical identification methods to analyze large datasets obtained from organic in vivo large- scale network-centric randomized experiments. His research spans two interrelated applied areas: the impact of information and communication technologies on education and peer-influence and consumption in the media industry. The bulk of his work is on medialytics, using big data analytics to understand the future of the media industry. In addition, Pedro has been studying competition, consumer churn, and switching costs in telecommunications. 


\section{Appendix A}

\section{An Estimation of Churn Rates}

Figure A1 shows the churn and survival rates obtained by using our multinomial choice model to explain consumer behavior. In particular, the churn rate is given by the market share of the churn alternative as estimated in column (1) of Table 3 . This figure shows that churn rates increase over time when the lock-in period is active. This is consistent with the fact that, the financial penalty that customers need to pay to churn, reduces as they near the end of the lock-in period. As expected, there is a significant increase in the probability of churn near the end of the lock-in period after which the likelihood of churn decreases smoothly because the customers that choose to stay with TELCO become increasingly more loyal over time.
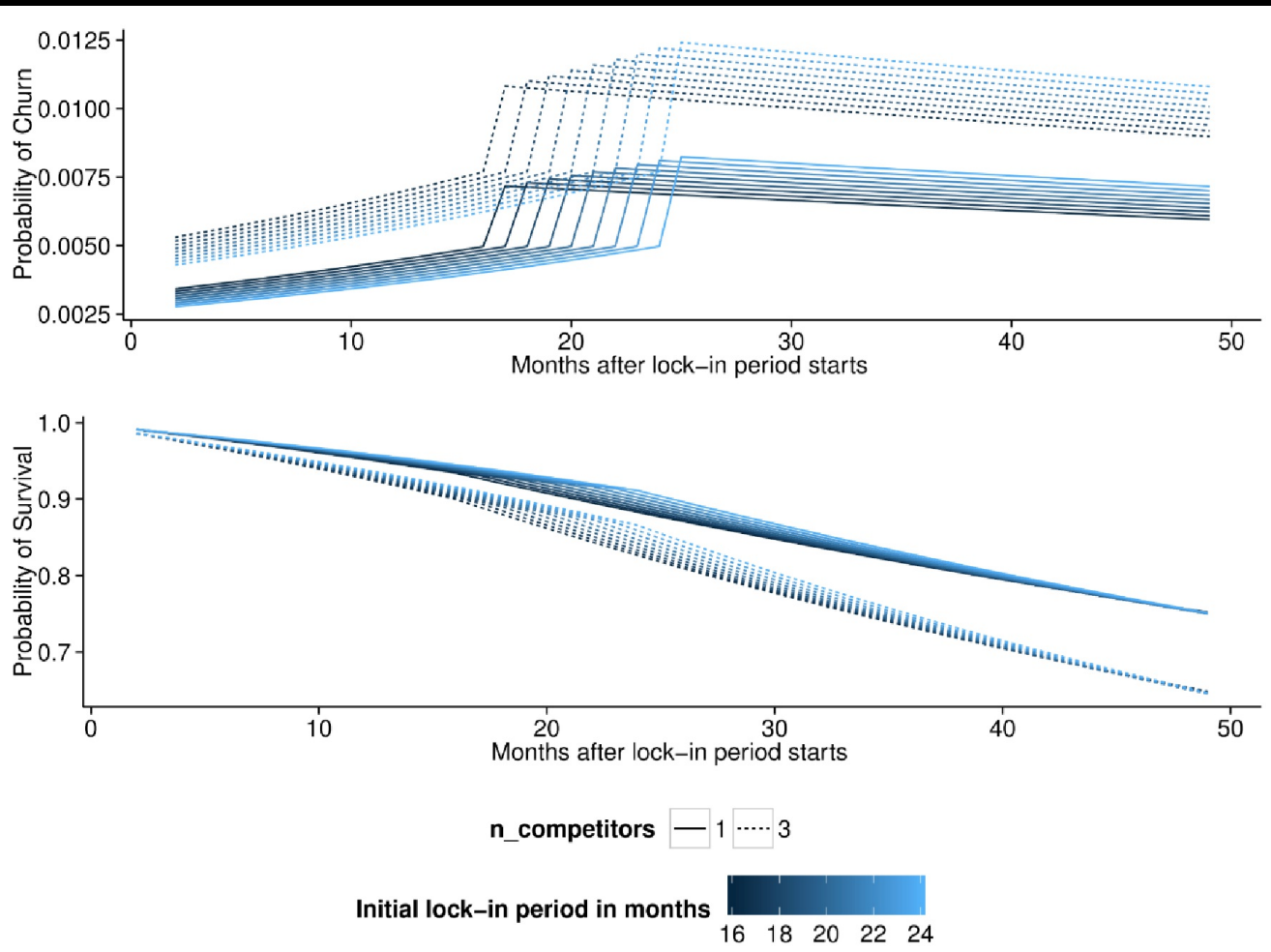

Estimated probability of churn (top) and probability of survival (bottom) when the length of the (initial) lock-in period varies. Results shown for when TELCO faces one and three competitors. Plots are based on simulations using the estimation results in column (1) of Table 3.

\section{Figure A1. Estimated Probability of Churn and Probability of Survival}

This figure also shows results for different initial lengths of the lock-in period, which allows us to observe that the probability of churn increases for shorter initial lock-in periods because the latter embody smaller switching costs. However, after the lock-in period expires, consumers with shorter initial lock-in periods churn less. This is likely to arise because in that case churners drop out earlier and thus the customers that remain are less prone to churn. In addition, it may also be the case that consumers that were locked into longer initial lock-in periods perceive the limitations associated to being locked-in differently and become relatively more willing to churn when lock-in periods shorten.

This figure also shows the probability of churn for different numbers of competitors. In markets with more firms, the baseline probability of churn is higher because consumers experience smaller switching costs ( and are positive and statistically significant in Table 3). 


\section{Appendix B}

\section{Simulation Results When Price Changes to Maintain Consumer Surplus}

We also use our simulation framework to determine the increase in prices that would render consumers indifferent with respect to changes in the length of the lock-in period. In other words, we now consider the case when the NRA allows firms to increase prices to recover part of their profit loss, but only to the extent that consumer surplus does not reduce. Figure B1 shows the results obtained. In the case of a market with TELCO and three other competitors and when consumers discount the future only slightly, the firm can increase prices by roughly $1 \%$ to counter a shortening of the lock-in period by 8 months without hurting consumer surplus. This increase in price is about $60 \%$ of the increase in price needed by firms to maintain profit levels. However, when consumers discount the future significantly, firms would only be allowed to slightly increase prices to not hurt consumers, namely $0.25 \%$ for the case above.
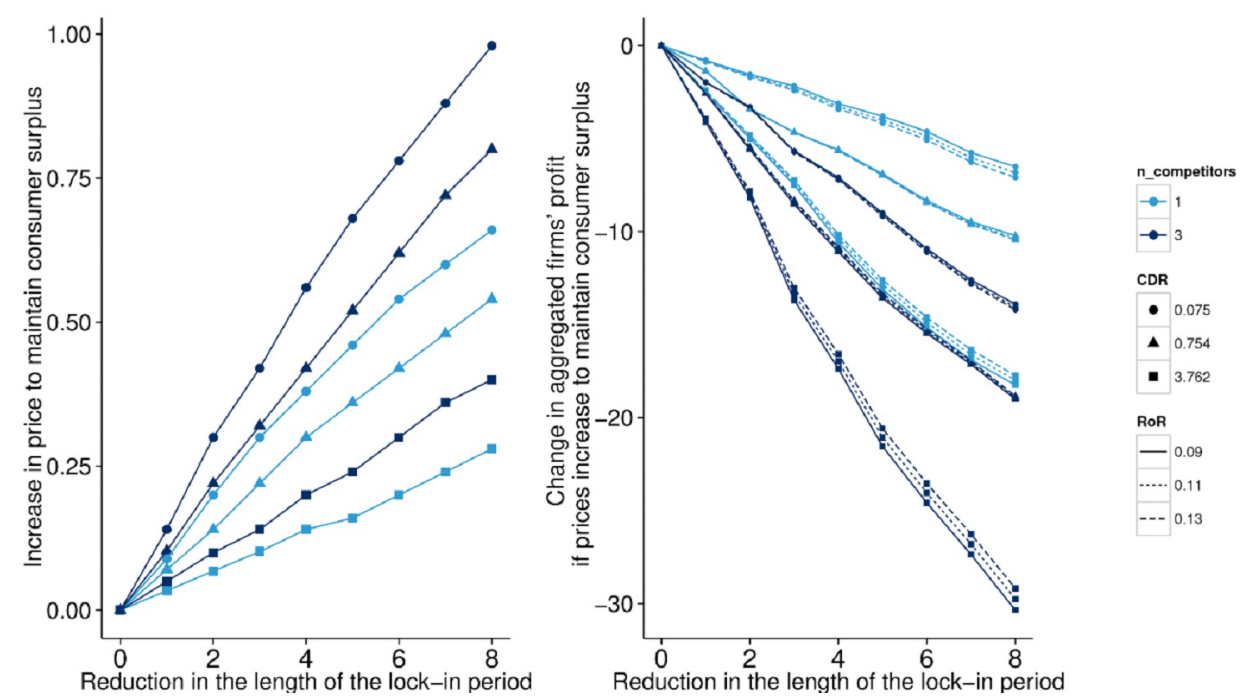

Increase in the price (in percentage terms) to keep consumer surplus unchanged (left) as a function of the shortening of the lock-in period and associated loss in aggregated firm profits (right). Results shown for when TELCO faces one and three competitors, for different CDR and different RoR. Plots are based on simulations using the estimation results in column (1) of Table 3.

\section{Figure B1. Increase in the Price to Keep Consumer Surplus Unchanged}

These results show us that policy interventions to cap prices may be unnecessary when consumers discount the future substantially because the benefits from reducing switching costs are also smaller. These results are qualitatively similar for the different rates of return rates that we simulate. In sum, this analysis shows how price regulation can be paired with shortening the lock-in period to protect the surplus of consumers and, at the same time, protecting some of the firms' profits. 


\section{Appendix C}

\section{Robustness Check for Simulations with Reduced Prices}
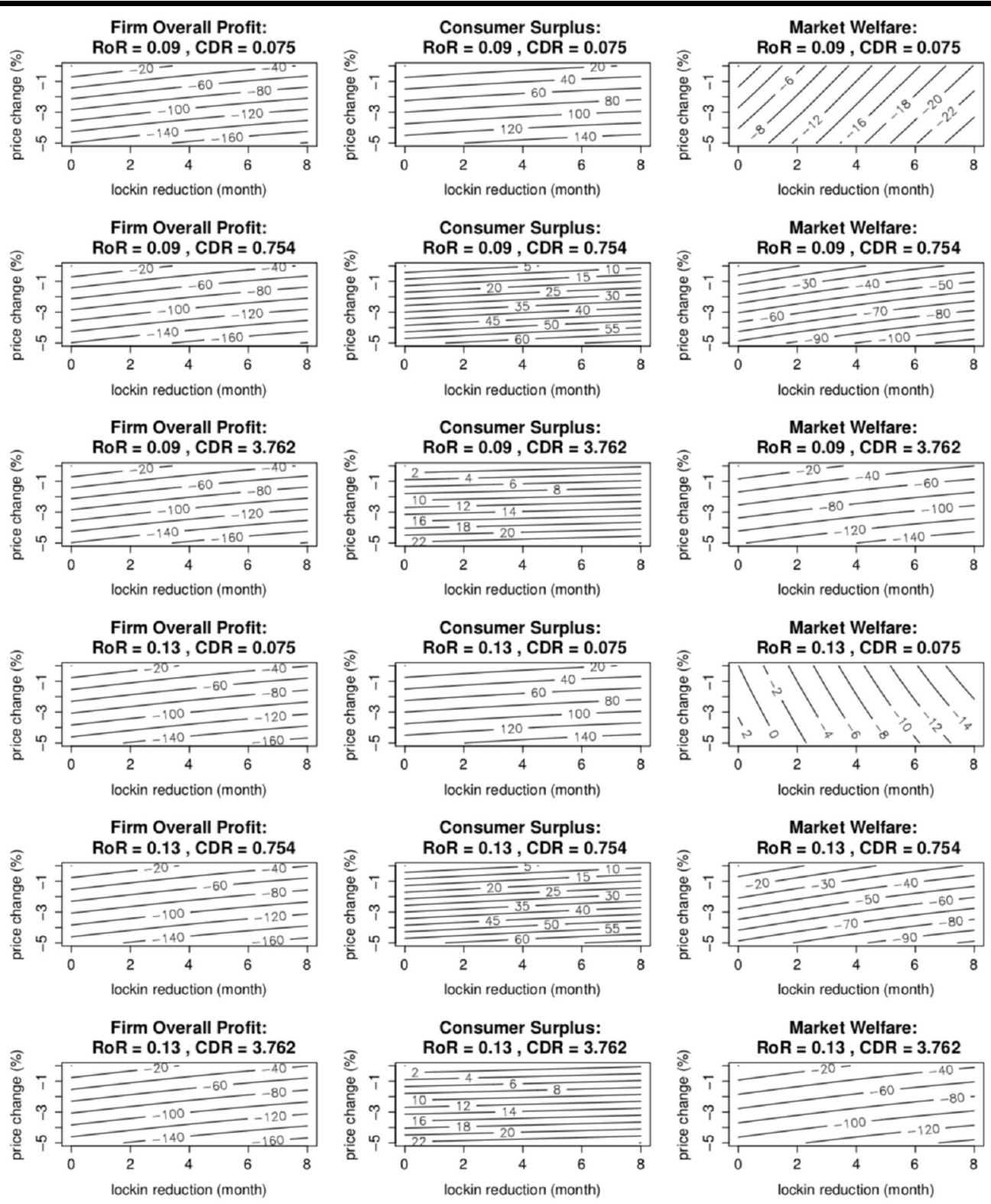

Contour plots for the joint effect of decreases in price (in percentage terms) and of reductions in the length of the lock-in period (in months) on aggregated firm profit (left column), consumer surplus (middle column), and total market welfare (right column) in a market with four providers. Results obtained using the estimation results in column (1) of Table 3.

Figure C1. Contour Plots for Joint Effect of Decreases in Price and Reductions in Length of Lock-in Period 
Copyright of MIS Quarterly is the property of MIS Quarterly and its content may not be copied or emailed to multiple sites or posted to a listserv without the copyright holder's express written permission. However, users may print, download, or email articles for individual use. 